\title{
Proposição de metodologia para determinação dos custos que compõem a hora técnica do perito que atua em litígios do Sistema Financeiro de Habitação
}

Idalberto José das Neves Júnior
Mestrado em Gestão do Conhecimento e Tecnologia da Informação pela Universidade
Católica de Brasília - UCB
Professor da Universidade Católica de Brasília - UCB Rua Ipê Amarelo, Lote 2/4, Bloco B, Apto. 204. Águas Claras/DF. CEP: 71908-000

E-mail: jneves@ucb.br

Adriano Mariano dos Santos

Graduação em Ciências Contábeis pela Universidade Católica de Brasília - UCB Rua 249, Quadra 108, Lote 19, Casa 02. Bairro Jardim Ingá. Luziânia/GO. CEP: 72853-

E-mail: mariano.adriano@gmail.com

Ismael Silva Candido

Graduação em Ciências Contábeis pela Universidade Católica de Brasília - UCB QR 319, Conjunto 05, Casa 06, Lote 01. Samambaia /DF. CEP: 72309-105

E-mail: ismael.candidois@gmail.com

\section{RESUMO}

A perícia constitui um importante ramo das Ciências Contábeis e uma das áreas mais promissoras para os profissionais Contabilistas. Todavia, existem poucas metodologias que auxiliem tais profissionais na determinação dos custos que fazem parte da sua hora técnica. Este artigo tem por finalidade construir um modelo que permita aos peritos contadores que trabalham com revisão de contratos do Sistema Financeiro de Habitação - SFH determinar os custos que compõem sua hora técnica. O método de custeio utilizado foi o Activity Based Costing (ABC), pois foi o que melhor se adequou na identificação dos custos envolvidos na produção do laudo pericial contábil. $\mathrm{Na}$ pesquisa utilizou-se uma amostra intencional, e por meio de resposta de 10 questionários respondidos pelos peritos que atuaram no ano de $2009 \mathrm{em}$ processos de revisão de contratos do SFH cadastrados nas Associações de Peritos Judiciais de Minas Gerais, Pernambuco e Distrito Federal pode-se atingir ao objetivo proposto. Como resultado, obteve-se que os profissionais dedicam maior parcela do seu tempo para executar o trabalho e não no planejamento do mesmo. Além disso, $24 \%$ dos recursos fornecidos para a execução das perícias não foram consumidos, gerando, assim, uma capacidade ociosa significativa para os profissionais que atuam nestes litígios.

Palavras-Chave: Perícia Contábil. Activity Based Costing - ABC. Sistema Financeiro de Habitação. 
Proposição de metodologia para determinação dos custos que compõem a hora técnica do perito
que atua em litígios do Sistema Financeiro de Habitação
Idalberto José das Neves Júnior, Adriano Mariano dos Santos, Ismael Silva Candido

\title{
Proposal of a methodology to determine the costs that compound the working hour of the accountant expert who works with litigations of the Housing Finance System based on the costing system ABC
}

\begin{abstract}
Forensic accounting is an important branch of Accountancy and one of the most promising areas for the accountants. However, there are few methods that help these workers identifying and measuring the resource consumption generated by their job. This paper aims to build a model which allows the accountant experts who work on contracts revision of the Housing Finance System (SFH) to determine the costs of their working hour. The costing model used was the Activity Based Costing (ABC), because it best fitted in the identification of the costs related to the production of the forensic accounting report. In the research it was used the intentional sampling and, through the answers of 10 questionnaires given by the accountant experts who worked in 2009 on lawsuits related to contract revision of the SFH and who have cadastre in the Associations of Assessors from Minas Gerais, Pernambuco and Distrito Federal, it was possible to reach the main purpose. As a result, it was noticed that these professionals spend most of their time doing the job itself, not planning it. Besides, 24\% of the supplied resources to make the investigation were not consumed, generating thus, a high idle capacity for the professionals who work on these litigations.
\end{abstract}

Key-words: Forensic Accounting. Activity Based Costing - ABC. Housing Finance System - SFH.

\section{INTRODUÇÃO}

Existem poucos trabalhos acadêmicos destinados ao estudo da Perícia Contábil, uma área bastante promissora no ramo de contabilidade e que exige profissionais hábeis e que possuam conhecimento não só dos Princípios e Normas contábeis, como também de outros assuntos alheios a esta ciência, mas que são imprescindíveis para a resolução dos litígios.

O exercício da função pericial exige do profissional amplo conhecimento da matéria conflituosa e elevado grau de dedicação e preparo. Entretanto, para Atkinson et. al. (2000, p. 84), "alguns elementos dos serviços são difíceis de mensurar diretamente, já que refletem a avaliação subjetiva dos clientes sobre vários atributos do produto". Dessa forma, os honorários devem refletir toda a complexidade e dedicação 
Proposição de metodologia para determinação dos custos que compõem a hora técnica do perito que atua em litígios do Sistema Financeiro de Habitação Idalberto José das Neves Júnior, Adriano Mariano dos Santos, Ismael Silva Candido

para a produção da prova pericial. Para isso, o perito deve dispor de uma metodologia que o auxilie nesta determinação.

Tendo em vista os vários campos em que pode ocorrer a solicitação de prova pericial, esta pesquisa evidencia apenas as perícias realizadas no âmbito do Sistema Financeiro de Habitação, já que, segundo Protásio (2007, p. 2), esta área apresenta-se de forma promissora, pois

muitas perícias na área da Contabilidade são hoje requeridas principalmente na parte de revisão de encargos financeiros contra bancos, principalmente referentes ao SFH, em virtude da complexidade do assunto decorrente das inúmeras ações do Governo Federal na tentativa de solucionar a questão habitacional no Brasil.

Em virtude desta crescente demanda nos processos de revisão de contratos habitacionais e os poucos estudos envolvendo pericias deste tipo, vê-se real fundamento para a elaboração desta proposta. O trabalho evidencia as fases, atividades, recursos consumidos e o tempo gasto na execução dos trabalhos, não tendo por objetivo propor uma metodologia para determinação do preço da hora técnica. Busca-se com isso determinar, apenas os custos presentes nas perícias do Sistema Financeiro de Habitação, fazendo-se uso do método de custeio ABC (ActivityBased Costing), pois este se mostrou ideal para determinação dos custos desta modalidade de atividade econômica.

Muito se discute sobre a real efetividade da utilização do sistema $A B C$ em organizações de serviços. Entretanto, como bem destacam Kaplan e Cooper (1998, p. 251), "as empresas de serviços são candidatas ideais ao custeio baseado na atividade, mais ainda que as empresas de produção (...)". Os autores ainda acrescentam os dois principais motivos "(...) primeiro todos os seus custos são indiretos e aparentemente fixos" e "(...) as empresas de serviços têm um volume mínimo ou não têm materiais diretos e a maior parte de seu pessoal oferece suporte indireto, e não direto, a produtos e clientes". 
Proposição de metodologia para determinação dos custos que compõem a hora técnica do perito que atua em litígios do Sistema Financeiro de Habitação Idalberto José das Neves Júnior, Adriano Mariano dos Santos, Ismael Silva Candido

Diante do exposto, o problema a ser respondido é: "Como determinar o custo da hora técnica do perito contador em ações revisionais de contratos do Sistema Financeiro de Habitação baseando-se na modelagem de Custeio ABC?". O objetivo geral é, portanto, propor uma metodologia baseada no custeio por atividades (ABC) para determinação dos custos como componente para a formação da hora técnica do perito judicial contábil que atua em processos de revisão de contratos do Sistema Financeiro de Habitação.

\section{REVISÃO DA LITERATURA}

\subsection{Fundamentos de Perícia Contábil}

Para Sá (2007, p. 13), "a perícia contábil é uma tecnologia, porque é a aplicação dos conhecimentos científicos de Contabilidade". Dessa forma, ao exercer a função pericial, o profissional usa esta tecnologia como instrumento para auxiliar o magistrado no processo decisório. Corroborando Sá, Hoog (2005, p. 50) conceitua perícia como, "(...) um serviço especializado com bases científicas, contábeis, fiscais e societárias, à qual se exige formação de nível superior, e deslinda questões judiciais e extrajudiciais". Estes aspectos muito importantes no desenvolvimento da atividade, pois destaca a interdisciplinaridade inerente a função de perito judicial oficial. Neste contexto, para Alberto (2002, p. 19), perícia é “(...) um instrumento especial de constatação, prova ou demonstração científica ou técnica, da veracidade de situações coisas ou fatos".

No âmago desta discussão, vale destacar a definição de Perícia emitida pelo Conselho Federal de Contabilidade por meio da NBC TP 01 Item 02:

A perícia contábil constitui o conjunto de procedimentos técnicos e científicos destinados a levar a instância decisória elementos de prova necessários a subsidiar a justa solução do litígio, mediante laudo contábil, e ou parecer pericial contábil, em conformidade com as normas jurídicas e profissionais, e a legislação específica que for pertinente. 
Proposição de metodologia para determinação dos custos que compõem a hora técnica do perito que atua em litígios do Sistema Financeiro de Habitação Idalberto José das Neves Júnior, Adriano Mariano dos Santos, Ismael Silva Candido

Dessa forma, Alberto (2002, p. 72) destaca que "o perito contador deve despirse de todos os preconceitos para ofertar aos cidadãos que submetem ao Estado-Juiz ou outra instância seu conflito a garantia de um serviço tecnicamente perfeito e moralmente isento e justo. " Esses fatores são materializados pelo perito judicial oficial em seu Laudo Pericial Contábil, instrumento esse que condensa sua experiência, conhecimento e domínio sobre a matéria conflituosa. Santos et al. (2006, p 65) destacam que "o laudo pericial consiste na exposição das operações e ocorrências da diligência, com o parecer fundamentado sobre a matéria que Ihes foi submetida".

Sá (2007, p. 18) ressalta que "vários são os fins para os quais se podem requerer uma perícia, mas como prova que ela vai ser, é preciso que se baseie em elementos verdadeiros e competentes". Como se pode notar, a prova pericial deve ser produzida com elementos verdadeiros para que o produto final não seja subavaliado ou contestado pelas partes envolvidas no litígio.

\subsection{Fases e procedimentos de uma perícia contábil}

Segundo Sá (2007, p. 34), "para planejar é preciso conhecer os recursos disponíveis, quer humanos, quer materiais, competentes pra produzir um laudo de qualidade". Este aspecto é de suma importância, pois a partir dele pode-se estimar a quantidade de horas e os custos envolvidos em cada etapa do planejamento. Não obstante, para o perito contador produzir uma prova pericial relevante, esta deverá estar amparada por um planejamento adequado.

Já Ornelas (2003, p. 71) menciona que "planejar trabalho pericial é, stricto sensu, ordenar os procedimentos técnicos a serem desenvolvidos pelo perito para obter os elementos que permitam oferecer o laudo pericial contábil". Acrescentando, Sá (2007, p. 36) explica que "para planejar o trabalho pericial é necessário conhecer a facilidade ou dificuldade que se pode ter para chegar até os dados que são objetos de exame (...)". Todavia, Ornelas (2003, p. 72), salienta que "para cada caso será necessário planejar ações e procedimentos específicos. Cada trabalho pericial a ser desenvolvido exige do perito um alto poder de conhecimento e criatividade técnica". Corroborando Ornelas, Ramaswamy (2007, p. 35) expõe que "em qualquer caso, o 

Proposição de metodologia para determinação dos custos que compõem a hora técnica do perito
que atua em litígios do Sistema Financeiro de Habitação

Idalberto José das Neves Júnior, Adriano Mariano dos Santos, Ismael Silva Candido

papel do perito contador é o estudo dos materiais e documentos relevantes, além da peça processual que está em mãos e que relata o fato"1.

Como visto, dada à relevância do tema, o Conselho Federal de Contabilidade por meio da NBC TP 01 delimitou as fases de planejamento, execução, procedimentos e laudo como sendo as principais etapas na realização de uma perícia contábil. Corroborando a NBC TP 01, Sá (2007, p. 65) expõe que "o ciclo da perícia judicial compõe-se da fase inicial, operacional e final, e estas de eventos distintos que formam todo o conjunto de ocorrências que caracterizam tais tarefas. "Dessa forma, ele estabelece as seguintes atividades para as fases mencionadas:

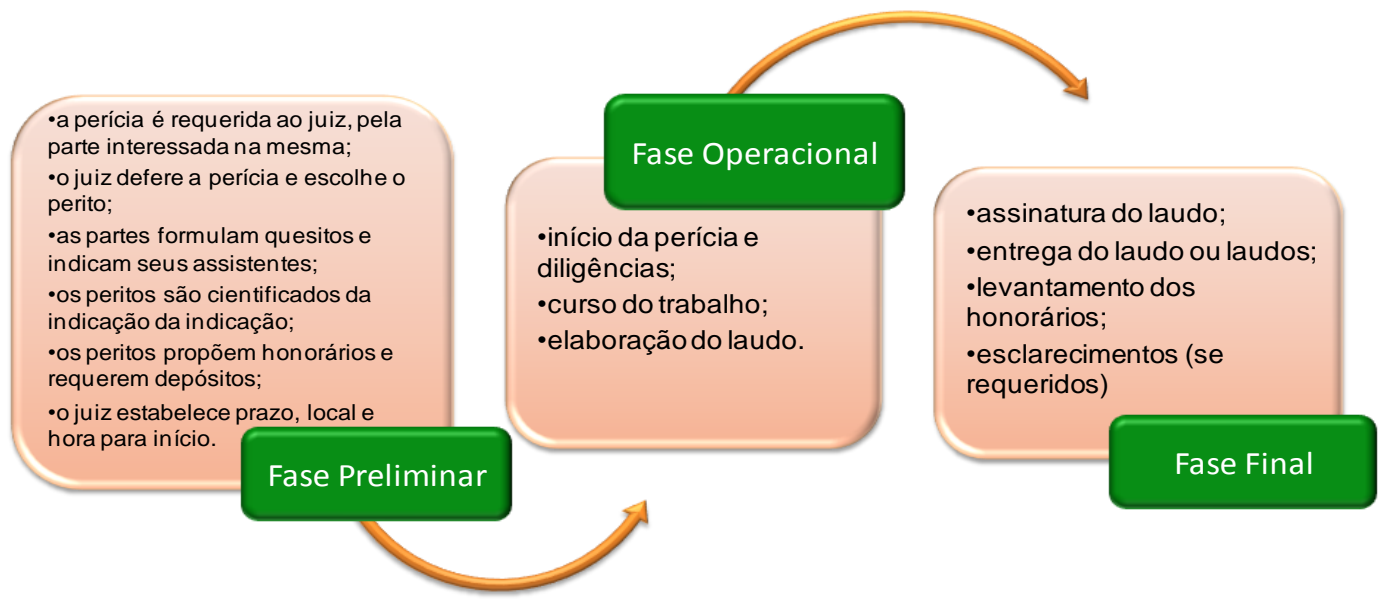

Figura 1: Processos Periciais Fonte: Sá (2007, p. 65).

Ademais, a NBC PP 01 estabeleceu algumas atividades que devem ser observadas para a elaboração do orçamento que fundamentará a petição de levantamento de honorários periciais. A Figura 2 apresenta a composição das atividades envolvidas em cada etapa da realização da perícia, usando como fundamentação a NBC TP 01, NBC PP 01 e a abordagem de Sá.

\footnotetext{
${ }^{1}$ Ramaswamy (2007, p. 35) "In either case, the role of the forensic accountant is to study relevant materials documents, and the authoritative literature relating to the case on hand."
} 
Proposição de metodologia para determinação dos custos que compõem a hora técnica do perito que atua em litígios do Sistema Financeiro de Habitação Idalberto José das Neves Júnior, Adriano Mariano dos Santos, Ismael Silva Candido

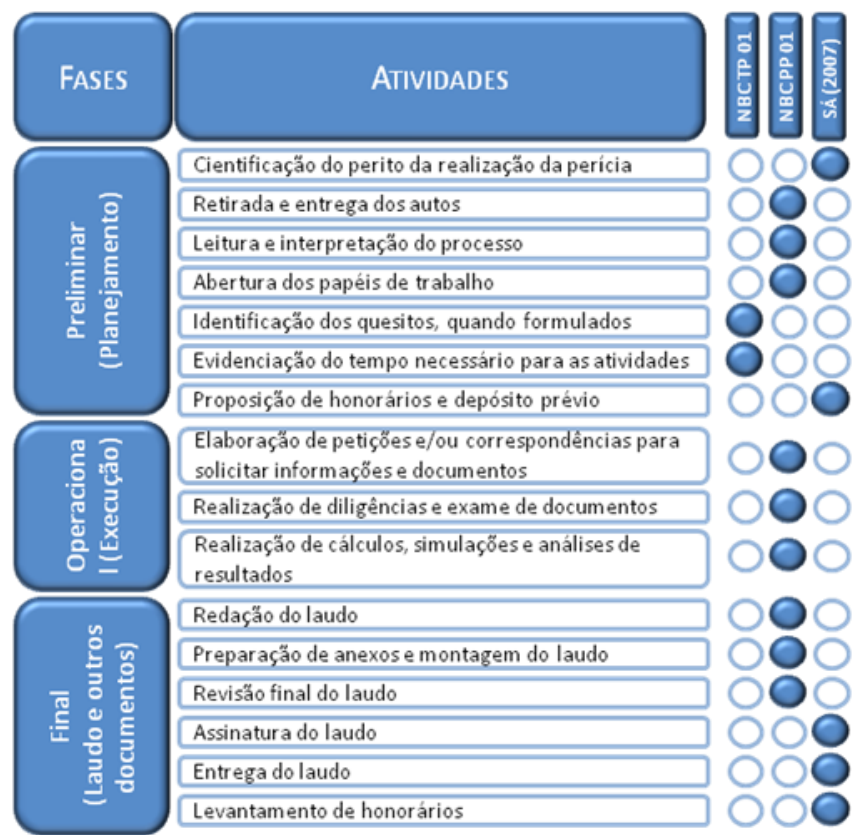

Figura 2: Fases e atividades de uma perícia Fonte: Adaptado: Sá (2007, p. 65), NBC TP 01 e NBC PP 01.

\subsection{Honorários Periciais Contábeis}

Segundo Hoog (2005, p. 159),

os honorários são a remuneração do perito e do assistente pelo serviço prestado. No entanto, consideramos ser uma parte muito delicada no relacionamento com o cliente, pois é neste momento que o perito estima a sua remuneração e apresenta ao juízo a sua proposta (...).

Dessa forma, o desempenho da função de Perito Oficial Judicial, como destaca Ramaswamy (2007, p. 37), requer “(...) conhecimentos de gestão financeira e contábil das empresas, habilidades avançadas em computação, um bom conhecimento do ambiente legal e forte habilidade de comunicação"2.

\footnotetext{
${ }^{2}$ Ramaswamy (2007, p. 37) "This requires knowledge of financial and managerial accounting, corporate financial management, advanced computer skills, a good knowledge of the legal environment, and strong communication skills."
} 
Proposição de metodologia para determinação dos custos que compõem a hora técnica do perito que atua em litígios do Sistema Financeiro de Habitação Idalberto José das Neves Júnior, Adriano Mariano dos Santos, Ismael Silva Candido

Entretanto, vale ressaltar que de acordo com artigo 33 do Código de Processo Civil, o pagamento pelos honorários será de responsabilidade de quem requereu o trabalho ou do autor no caso de ambos solicitarem o exame e, em outra hipótese, determinado de ofício pelo juiz.

Para subsidiar a decisão do magistrado, em relação ao arbitramento, o perito judicial deve fundamentar seu pedido de honorários adequadamente. Dessa forma, estabelece Ornelas (2003, p. 110), que "na petição de requerimento do arbitramento de seus honorários, o perito fará uma exposição resumida, dos principais eventos de seu trabalho, a título de embasamento e justificativa para o valor requerido".

Este embasamento pode ser realizado mediante a consulta aos conselhos regionais e associações de contabilidade. Neste sentido, para Alberto (2002, p. 92), "ao fundamentar o pedido, por dever ético, o perito contábil o fará segundo os parâmetros estabelecidos em sua região e devidamente aprovado pelo Conselho Regional de Contabilidade (...)".

É comum observar a dificuldade enfrentada pelo profissional contábil para a correta mensuração do valor de sua hora técnica, dada a diversidade de áreas que um perito pode atuar. Neste contexto, de acordo com Vendrame (2005, p. 02),

outro ponto controvertido na vida do Perito, ainda é a questão dos honorários periciais. De um lado o Perito, como qualquer outro profissional, deve receber uma justa paga pelo seu trabalho; de outro lado, não existe qualquer dispositivo legal regulando o quantum desses honorários, exceto algumas tabelas propostas por associações, que ainda não se enquadram a todos os tipos de perícia.

Com isso, uma metodologia poderá ser proposta desde que se delimite a um determinado tipo de perícia, no caso, revisão de contratos do sistema financeiro de habitação, por se tratar de uma área de forte demanda do magistrado para auxiliá-lo no processo decisório. Além disso, a metodologia poderá reduzir a contestação das partes em relação ao valor cobrado. 
Proposição de metodologia para determinação dos custos que compõem a hora técnica do perito que atua em litígios do Sistema Financeiro de Habitação Idalberto José das Neves Júnior, Adriano Mariano dos Santos, Ismael Silva Candido

De acordo com Santos et al. (2006), cabe ao perito contador apresentar de forma clara os procedimentos a serem adotados. Este fator, associado ao embasamento jurídico pertinente, diminuirá sobremaneira as contestações das partes envolvidas quanto ao pedido de arbitramento de honorários.

\subsection{Sistema Financeiro de Habitação (SFH)}

Com o advento da Lei 4.380 em agosto de 1964, foi criado o Sistema Financeiro de Habitação (SFH), cujo objetivo é exposto em seu artigo 08 como "facilitar e promover a construção e a aquisição da casa própria ou moradia, especialmente pelas classes de menor renda da população" (BRASIL, 1964).

Nesta mesma lei foi criado, também, o Banco Nacional de Habitação (BNH) que tinha por finalidade o de orientar, disciplinar e controlar o sistema financeiro de habitação, porém não operava diretamente com o financiamento, compra e venda ou construção de habitações (BRASIL, 1964), ficando exclusivamente como órgão orientador, disciplinador e de assistência financeira.

As tentativas do governo em reduzir a burocracia para a concessão de crédito acabou gerando um complexo método de cálculo para se chegar ao valor das prestações, o que acabou gerando um aumento de infrações nestes contratos, que consequentemente, culminou no crescimento do número de perícias neste sentido. Com isso, o objetivo das ações revisionais de contratos tornou-se o "restabelecer a renda justa e real do imóvel, equivalente ao seu valor no mercado" (FRANCO, 1992, p. 72).

Conforme dados apresentados no sítio da Empresa Gestora de Ativos (EMGEA), dos 1.193.298 contratos cedidos ao órgão pela Caixa Econômica Federal (CEF) para serem geridos até o fim do referido crédito (dados até 28.02.2010) 23\% ficam inadimplentes e $5 \%$ são renegociados. Além disso, dos 360.248 contratos ativos no Estado (dados coletados até julho de 2009), 48,16\% estão inadimplidos, ou seja, constam três ou mais parcelas em atraso.

Para Protásio (2007), as formas de crédito oferecidas pelo mercado para facilitar a aquisição da casa própria acabaram sendo utilizadas pelos agentes 
Proposição de metodologia para determinação dos custos que compõem a hora técnica do perito que atua em litígios do Sistema Financeiro de Habitação Idalberto José das Neves Júnior, Adriano Mariano dos Santos, Ismael Silva Candido

financiadores para se obter ganhos maiores, por conta das altas taxas de juros. As complexidades dos cálculos utilizados para manutenção das prestações assustam muitos usuários, que apenas observam o crescimento absurdo de suas dívidas.

Hoog (2005, p. 374) coloca que os principais conflitos judiciais são: Capitalização de juros; Usura, ou seja, lucros discricionários; e adoção de critério ou método de amortização a juros simples, pois, segundo ele os contratos do SFH "agasalham de forma oculta a capitalização dos juros".

Porém, em todos os casos se faz necessária à perícia contábil para se provar "certificação científica e tecnológica" se existiu, ou não, a capitalização e/ou excesso de juros e o seu montante (HOOG, 2005, p. 374).

\subsection{Sistema de Custeio Baseado em Atividades (ABC)}

Para Kaplan e Cooper (1998, p. 94), "um modelo ABC é um mapa econômico das despesas e da lucratividade da organização baseada nas atividades.". Complementando, Brimson (1996, p. 39) expõe que "as informações de custos por atividade fornecem uma visão clara de como a combinação de diversos produtos, serviços e atividades de uma empresa contribuem ao final para o resultado. "Para Martins (2006, p. 139), este método “ (...) procura reduzir sensivelmente as distorções provocadas pelo rateio arbitrário dos custos indiretos" e, ainda, permite o levantamento do quanto se gasta em determinadas atividades, tarefas e processos".

Sendo assim, Kaplan e Cooper (1998, p. 01) salientam que "(...) se as informações de custo do produto são distorcidas, a empresa pode seguir uma estratégia inadequada e inútil". ${ }^{3}$ Dessa forma, o objetivo do custeio por atividades não é mais ajudar a alocar adequadamente os custos, mas descobrir os motivos que levam as organizações a consumirem recursos.

Nesse contexto, Brimson (1996, p. 27) argumenta que "a função principal de uma atividade é converter recursos (material, mão de obra e tecnologia) em produção (produtos/serviços). " Contudo, para uma modelagem ABC ser efetivamente implantada

\footnotetext{
${ }^{3}$ Kaplan e Cooper (1998, p. 01) "If the product cost information is distorted, the firm can follow an inappropriate and unprofitable strategy."
} 
Proposição de metodologia para determinação dos custos que compõem a hora técnica do perito que atua em litígios do Sistema Financeiro de Habitação Idalberto José das Neves Júnior, Adriano Mariano dos Santos, Ismael Silva Candido

é preciso que se conheçam os produtos que serão gerados pelo profissional contábil. Como já comentado, o trabalho estudará apenas um produto; o laudo pericial contábil.

Considerados os procedimentos e visando dirimir possíveis contestações é necessário fundamentar bem o pedido de honorários. Sendo assim, Cogan (1999a) estabelece que a implantação do sistema $A B C$ deve obedecer às etapas apresentadas na Figura 3.

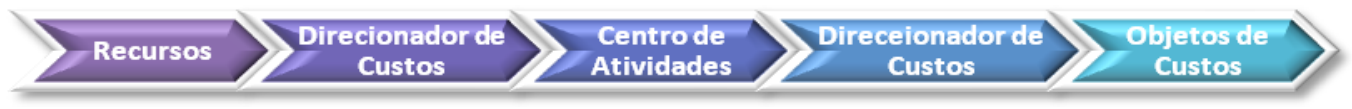

Figura 3: Distribuição dos custos aos objetos de custos pelo $A B C$ Fonte: Cogan (1999a, p. 37).

Segundo Cogan (1999a), uma suposição do ABC é que todos os custos de cada centro de atividades funcionam como se variáveis fossem mantendo proporcionalidade com a respectiva atividade. O direcionador de custos é o critério utilizado para demonstrar a relação de custos de acordo com os objetos de custo e a interação causal entre o consumo de recursos e a utilização das atividades pelos objetos de custos.

Todavia, vale destacar a gestão da capacidade não utilizada que é uma importante ferramenta fornecida pelo ABC. Portanto, de acordo com Kaplan e Cooper (1998), a equação fundamental para medir o custo dos recursos fornecidos segue o exposto na Figura 4.

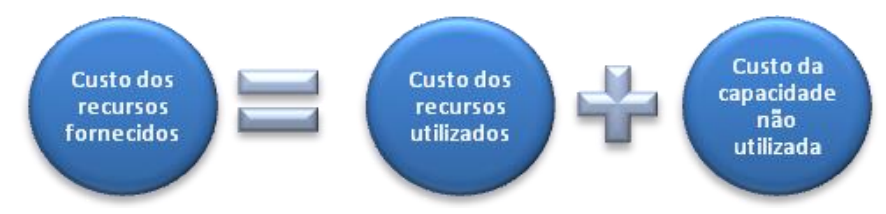

Figura 4: Equação fundamental para medição do custo de capacidade Fonte: Baseado em Kaplan e Cooper (1998).

Corroborando o exposto por Kaplan e Cooper, Maher (2001, p. 320) coloca que "os recursos fornecidos a uma atividade representam os gastos efetuados na atividade". O mesmo autor observa em outra passagem que “(...) as companhias têm que pagar 
Proposição de metodologia para determinação dos custos que compõem a hora técnica do perito que atua em litígios do Sistema Financeiro de Habitação Idalberto José das Neves Júnior, Adriano Mariano dos Santos, Ismael Silva Candido

por recursos fornecidos, mesmo que eles não sejam totalmente utilizados". Nesse contexto, Kaplan e Cooper (1998, p. 138) salientam que "a demanda reduzida de recursos organizacionais reduzirá o custo dos recursos utilizados (por produtos, serviços e clientes), mas essa redução será compensada por um aumento equivalente da capacidade não utilizada".

A gestão desta capacidade não utilizada é uma das principais ferramentas fornecidas pelo ABC e como destaca Maher (2001, p. 323), “(...) a administração precisa fazer com que os recursos utilizados por uma atividade e os recursos a ela fornecidos tenham correspondência tão próxima quanto possível".

O sistema $A B C$ é mais comumente usado para indústrias e comércios, mas conforme Drucker (1999, p.01), "é provável que seu maior impacto esteja em serviços"4. Complementando Drucker, Kaplan (1999, p. 09) assinala que "o ABC é uma técnica que pode ser aplicada às empresas prestadoras de serviços, na verdade, estas enfrentam problemas ainda mais difíceis que os de companhias industriais, pois basicamente todas as suas despesas são indiretas".

Para que os peritos possam utilizar o sistema $A B C$, eles se valem do método mais simples que Cooper e Kaplan (1991 apud COGAN, 1999a, p. 7) definem como aquele que "agrega os gastos em todos os recursos destinados àquela atividade particular e divide esse dispêndio total pelo número de vezes que a atividade foi realizada". Para Kaplan e Cooper (1998) o sistema ABC é composto basicamente por quatro etapas:

${ }^{4}$ Druker (1999, p. 01) "(...) its greatest impact is likely to be in services.” 
Proposição de metodologia para determinação dos custos que compõem a hora técnica do perito que atua em litígios do Sistema Financeiro de Habitação Idalberto José das Neves Júnior, Adriano Mariano dos Santos, Ismael Silva Candido

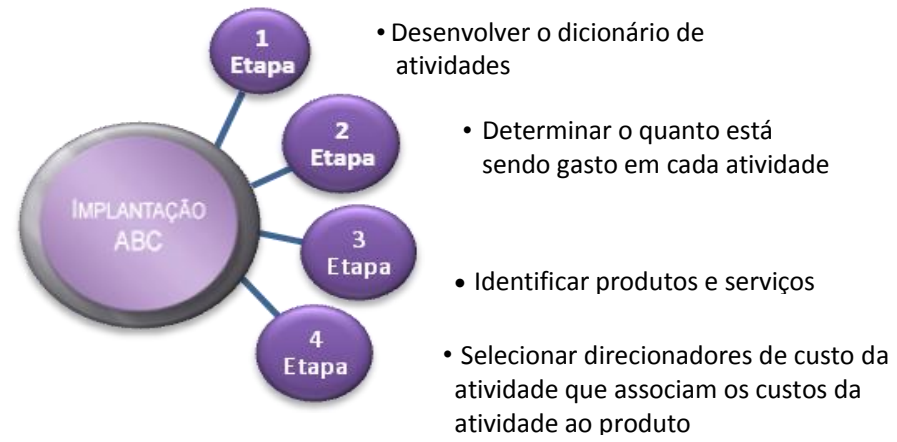

Figura 5: Metodologia de Kaplan e Cooper para implantação do ABC Fonte: Baseado em Kaplan e Cooper (1998).

Brimson (1996) estabelece que o ABC é um processo de melhoria de feedback, pois permite a melhoria contínua das atividades e processos em questão. No ABC o custo de um produto é o conjunto de todos os custos das atividades realizadas para gerar o produto, neste caso, o processo. Todavia, vale ressaltar que as atividades estão interligadas e a sua execução de forma coordenada determina a eficácia do modelo de custeio. Para isso é importante distinguir os processos das atividades. Para Boisvert (1999, p. 57), "processo é um conjunto de atividades que têm um direcionador comum e um objetivo bem preciso que possa ser identificado ao cliente interno ou externo."

Para Atkinson et al. (2000, p. 77), "uma atividade é uma unidade de trabalho, ou tarefa, com objetivo específico. " Todavia, Boisvert (1999, p. 55) ressalta que "a tarefa é o elemento mais simples da atividade". Nesse contexto, pode-se observar que a estrutura de procedimentos é formada pelos processos, atividades e tarefas.

No entanto, para se ter uma visão clara de como as atividades consomem recursos, é preciso que existam direcionadores que associem os custos às atividades. Nesse aspecto, Kaplan e Cooper (1998, p.101) estabelecem que "os geradores de custos de recursos associam os gastos e as despesas, conforme informações geradas pelo sistema financeiro ou contábil da organização, às atividades executadas".

Desta forma, os recursos são as ferramentas que o perito contador utiliza para realização de suas atividades. Sendo assim, Brimson (1996, p. 28) expõe que "os recursos consistem em pessoas, máquinas, viagens, suprimentos, sistemas de 
Proposição de metodologia para determinação dos custos que compõem a hora técnica do perito que atua em litígios do Sistema Financeiro de Habitação Idalberto José das Neves Júnior, Adriano Mariano dos Santos, Ismael Silva Candido

computadores e outros (...)". O autor estabelece como grupos de recursos consumidos: tecnologia, mão-de-obra direta e material direto.

O material direto consiste nos custos de todas as atividades necessárias para trazer o material para o processo de produção. Tecnologia como todos os custos relacionados à aquisição e operação de elementos tecnológicos e, por fim, a mão-deobra direta como sendo todos os recursos relacionados com a contratação, treinamento e apoio de pessoal (BRIMSON, 1996). Os insumos constituem outro importante grupo que deve ser considerado. Dessa forma, insumo pode ser definido como a soma dos fatores da produção consumidos no processo de elaboração de determinado resultado. (BELCHIOR, 1987).

O passo final para a conclusão da modelagem $A B C$ é a atribuição das atividades aos objetos de custo. Nesse contexto, Kaplan e Cooper (1998, p. 109) esclarecem que "a ligação entre atividade e objetos de custo como produtos, serviços e clientes é feita por meio de geradores de custo da atividade".

\section{PESQUISA EMPÍRICA}

\subsection{Síntese da Pesquisa}

A pesquisa tem por objetivo propor uma metodologia baseada no custeio por atividades $(A B C)$, para determinação dos custos como componente para a formação da hora técnica do perito judicial contábil que atua em processos de revisão de contratos do Sistema Financeiro de Habitação.

Dessa forma, os dados foram obtidos mediante a aplicação de questionário a Peritos Judiciais Contábeis que já atuaram em processos de revisão de contratos de financiamento habitacional cadastrados no INPECON do Distrito Federal, na Associação de Peritos Judiciais de Pernambuco e Minas Gerais. Os dados foram tabulados utilizando-se a ferramenta Excel e, posteriormente, analisados utilizando técnicas como análise de conteúdo e método da raiz com o propósito de organizá-los visando atingir os objetivos propostos na pesquisa. 
Proposição de metodologia para determinação dos custos que compõem a hora técnica do perito que atua em litígios do Sistema Financeiro de Habitação Idalberto José das Neves Júnior, Adriano Mariano dos Santos, Ismael Silva Candido

\subsection{Participantes da pesquisa}

O instrumento de pesquisa foi aplicado a todos os Peritos Contadores cadastrados no INPECOM - Instituto dos Peritos e Consultores Técnicos do Distrito Federal, Associação de Peritos Judiciais de Pernambuco e Minas Gerais. No Gráfico 1 apresenta-se o percentual de contratos do SFH por Estado:

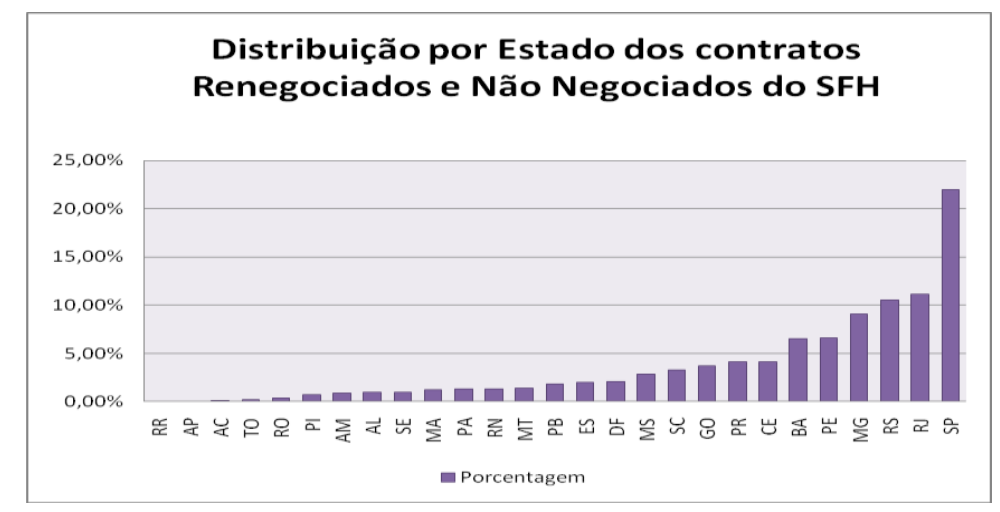

Gráfico 1: Distribuição por Estado dos Contratos Renegociados e Não Negociados Fonte: Dados EMGEA.

Como parâmetro para a escolha dos estados utilizou-se o sítio do EMGEA, o qual dispunha os dados relacionados aos contratos do SFH. Foram considerados todos os estados com concentração acima de $5 \%$ dos contratos renegociados e não negociados, mais o Distrito Federal, por se ter maior acesso aos peritos deste conglomerado. Visto a dificuldade de acesso a alguns estados como Bahia, onde não há fonte contendo os dados da Associação de Peritos e Rio Grande do Sul, Rio de Janeiro e São Paulo, de onde não foram obtidas respostas, optou-se pelos estados citados anteriormente.

A amostragem da pesquisa é intencional, não probabilística. De acordo com Silva (2006, p. 75), "a amostragem não probabilística intencional é aquela que escolhe cuidadosamente os casos a serem incluídos na amostra, e produz amostras satisfatórias em relação a suas necessidades".

Obteve-se resposta de 10 questionários, compondo assim a amostra trabalhada na confecção do artigo. Entretanto, vale destacar que foi realizada uma fase de pré- 
Proposição de metodologia para determinação dos custos que compõem a hora técnica do perito que atua em litígios do Sistema Financeiro de Habitação Idalberto José das Neves Júnior, Adriano Mariano dos Santos, Ismael Silva Candido

teste com cinco peritos contadores com o objetivo de se fazer melhorias no questionário.

\subsection{Métodos Utilizados para a Coleta de Dados}

Fundamentando este estudo foram utilizados os seguintes conceitos, a saber:

\begin{tabular}{|c|c|}
\hline $\begin{array}{c}\text { Fundamentos da Perícia } \\
\text { Contábil }\end{array}$ & -Sá (2005), Alberto (2002), Hoog (2008) e CFC (2009) \\
\hline $\begin{array}{l}\text { Fases e Procedimentos de } \\
\text { uma perícia contábil }\end{array}$ & • Ornelas (2003), Sá (2005), CFC (2009) \\
\hline Honorários Periciais & •Hoog (2007), Alberto (2002) e Ornelas (2003) \\
\hline $\begin{array}{c}\text { Sistema Financeiro de } \\
\text { Habitação }\end{array}$ & -Brasil (Lei 4380/64), Franco (1992) e Hoog (2007) \\
\hline Sistema de Custeio ABC & $\begin{array}{l}\text { - Martins (2006), Kaplan (1999), Cogan (1994) } \\
\text { Boisvert (1999) e Kaplan e Cooper (1998) }\end{array}$ \\
\hline
\end{tabular}

Figura 6: Fundamentação para o estudo

O questionário para construção do modelo foi dividido em duas (2) partes. A primeira evidenciou os dados pessoais dos entrevistados e a segunda consistiu na obtenção das atividades, recursos consumidos e tempo gasto em perícias no âmbito do Sistema Financeiro de Habitação, uma vez que estes são os elementos essenciais para construção de um modelo para determinação do custo da hora técnica pelo sistema ABC. Na elaboração do questionário foram utilizados os conteúdos apresentados na Figura 6.

Além disso, para criar o quadro das atividades compilaram-se as respostas fornecidas pelos peritos. Desta forma, para destacar o número de elementos por categoria, foi aplicada a técnica da raiz que consiste na utilização da seguinte equação; $\mathrm{K}=\sqrt{ } \mathrm{n}$. Onde, $\mathbf{K}$ é o número de classes e $\mathbf{n}$ é o número de elementos (ERMES et al., 1999).

\subsection{Protocolo de Pesquisa}

No trabalho foram adotados os procedimentos constantes na Figura 7. 
Proposição de metodologia para determinação dos custos que compõem a hora técnica do perito que atua em litígios do Sistema Financeiro de Habitação Idalberto José das Neves Júnior, Adriano Mariano dos Santos, Ismael Silva Candido

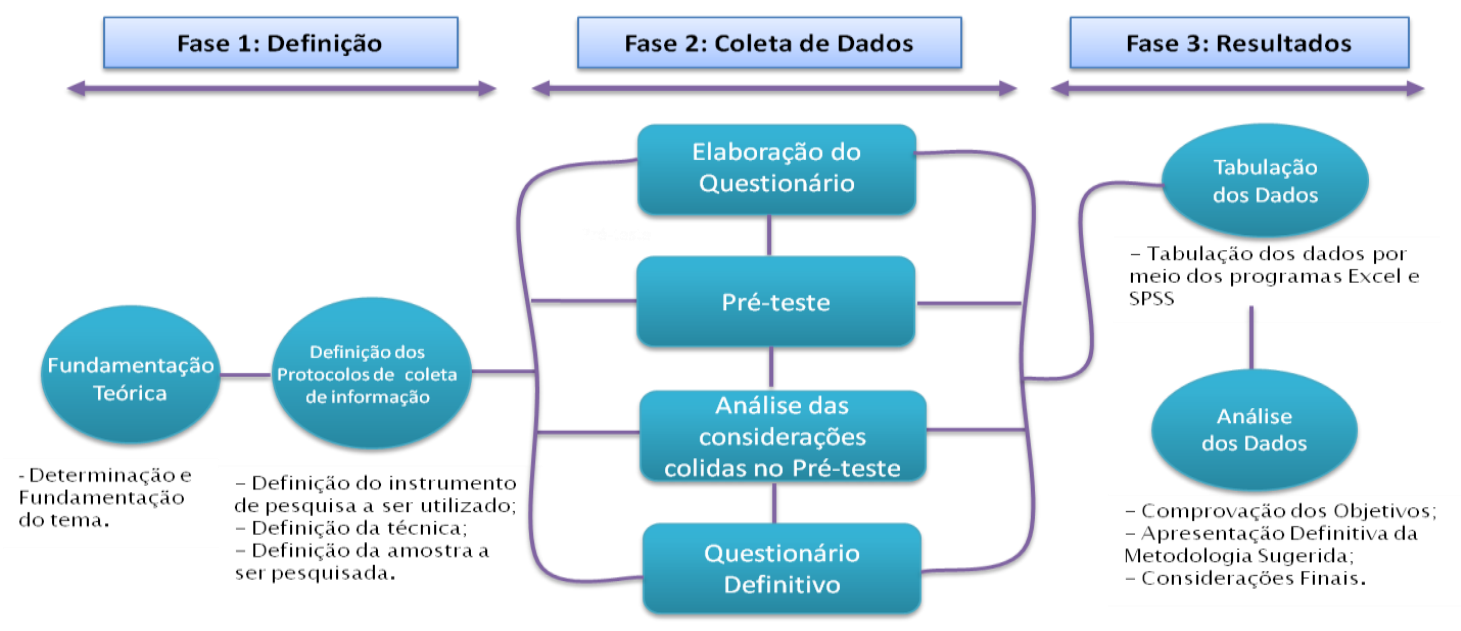

Figura 7: Procedimentos adotados

\section{RESULTADOS}

Os resultados são apresentados nas próximas seções seguindo a metodologia de custeio $A B C$ abordada na revisão da literatura, buscando sempre contextualizar tais informações de custos com a área de Perícia Contábil.

Dessa forma, esta seção contempla a percepção dos peritos em relação à existência de uma metodologia para determinação dos custos que estão presentes em sua hora técnica e a apresentação do modelo de Custeio $A B C$ voltado para perícias realizadas no âmbito do SFH. No Gráfico 2, consta o tempo de experiência, em anos, dos participantes da pesquisa.

Tempo de experiência

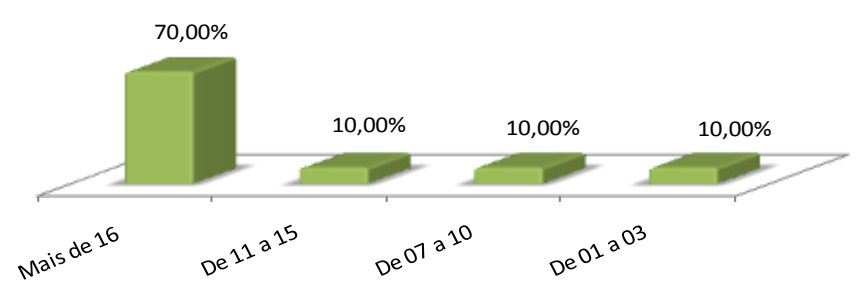

Gráfico 2: Tempo de experiência dos peritos

Fonte: Dados da pesquisa. 
Proposição de metodologia para determinação dos custos que compõem a hora técnica do perito que atua em litígios do Sistema Financeiro de Habitação Idalberto José das Neves Júnior, Adriano Mariano dos Santos, Ismael Silva Candido

\subsection{Percepção dos peritos em relação à utilidade do estudo}

Para Ornelas (2003), cada trabalho pericial a ser desenvolvido exige do perito um alto poder de conhecimento e criatividade técnica. Assim, perguntou-se aos respondentes se as perícias do SFH possuíam peculiaridades que as tornavam diferentes das demais. Observa-se que $90 \%$ dos respondentes concordam que há tais peculiaridades (Gráfico 3).

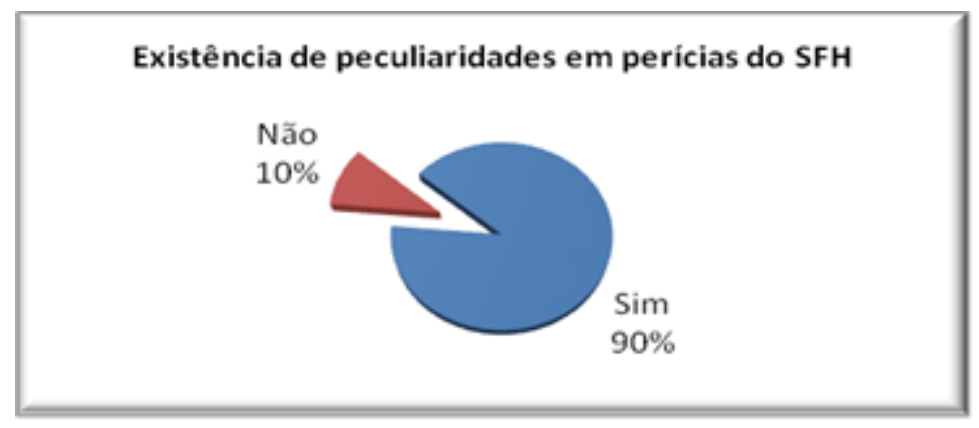

Gráfico 3: Existência ou não de peculiaridades em perícia do SFH Fonte: Dados da pesquisa.

Brimson (1996, p. 39) ressalta que "as informações de custos por atividade fornecem uma visão clara de como a combinação de diversos produtos, serviços e atividades de uma empresa contribuem ao final para o resultado". Baseado nisso, fezse a seguinte afirmação aos peritos: "O mapeamento dos processos, atividades, recursos consumidos e tempo gasto, permitem capturar as peculiaridades apresentadas pela execução de perícias no âmbito do Sistema Financeiro da Habitação (SFH) ".

Utilizando a escala Likert de concordância, chega-se ao resultado apresentado no Gráfico 4. 
Proposição de metodologia para determinação dos custos que compõem a hora técnica do perito que atua em litígios do Sistema Financeiro de Habitação Idalberto José das Neves Júnior, Adriano Mariano dos Santos, Ismael Silva Candido

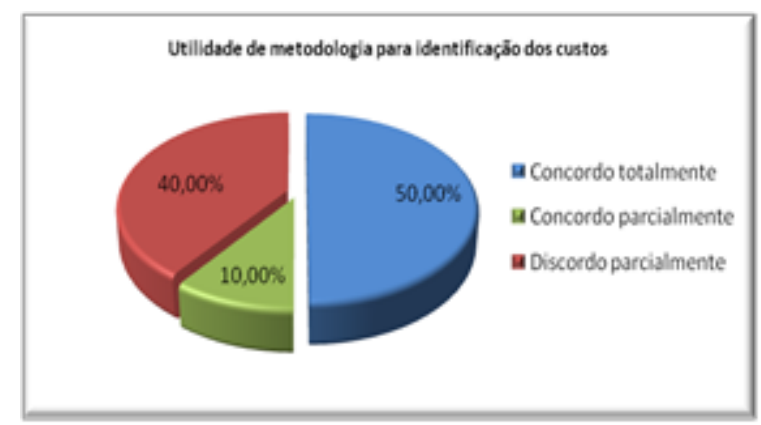

Gráfico 4: Utilidade de metodologia para determinação dos custos Fonte: Dados da pesquisa.

De acordo com os participantes da pesquisa, existem peculiaridades que diferenciam este tipo de perícia e que uma metodologia que capture tais especificidades inerentes à atividade de perito judicial poderia ser útil no desenvolvimento dos trabalhos.

\subsection{Identificação das atividades presentes em perícias do SFH}

Como abordado nas seções anteriores, a primeira etapa da construção de um modelo baseado no sistema $A B C$ é a identificação das atividades presentes no desenvolvimento de perícias do SFH. Dessa forma, no questionário foi solicitado aos respondentes que apresentassem as atividades, fase e grau de dedicação a estas tarefas. No entanto, vale destacar que as fases foram estabelecidas previamente em planejamento operacional e final, com base na literatura analisada e que ao invés de perguntar o tempo despendido por atividade, foi solicitado que os peritos expusessem o grau de dedicação às mesmas em termos percentuais.

Inicialmente identificou-se o tempo gasto em média pelos participantes da pesquisa na realização de uma perícia no âmbito do $\mathrm{SFH}$, chegando-se a um quantitativo de 28 horas e 36 minutos.

Após uma pré-análise e um estudo detalhado das principais tarefas listadas pelos respondentes, pode-se chegar a um quadro de atividades geralmente realizadas em litígios do SFH e a um grau de dedicação médio dedicado às mesmas. 
Proposição de metodologia para determinação dos custos que compõem a hora técnica do perito que atua em litígios do Sistema Financeiro de Habitação Idalberto José das Neves Júnior, Adriano Mariano dos Santos, Ismael Silva Candido

Tabela 1: Fases e atividades

\begin{tabular}{|c|c|c|}
\hline FASES E ATIVIDADES & OCORRÊNCIAS & $\begin{array}{c}\text { DEDICAÇÃo } \\
\text { MÉDIA }\end{array}$ \\
\hline PLANEJAMENTo & 10 & $10,60 \%$ \\
\hline Retirada e Análise dos autos & 4 & $4,50 \%$ \\
\hline $\begin{array}{c}\text { Estimativa do tempo e Identificação da metodologia a ser } \\
\text { adotada }\end{array}$ & 6 & $6,10 \%$ \\
\hline OPERAcıonAL & 39 & $56,70 \%$ \\
\hline Recolhimento e Análise das peças processuais & 14 & $22,00 \%$ \\
\hline Elaboração de planilhas e Efetuação de cálculos & 11 & $20,80 \%$ \\
\hline Análise e Resposta aos quesitos & 6 & $7,50 \%$ \\
\hline Exame da tabela do agente Financeiro & 3 & $2,50 \%$ \\
\hline Exame da legislação vigente & 3 & $2,40 \%$ \\
\hline Reunião com Assistentes & 2 & $1,50 \%$ \\
\hline FinAL & 23 & $32,70 \%$ \\
\hline Elaboração e Revisão do Laudo & 15 & $24,80 \%$ \\
\hline Resposta a quesitos adicionais & 3 & $3,00 \%$ \\
\hline Revisão de cálculos & 2 & $3,00 \%$ \\
\hline Confecção dos anexos e Petição de honorários & 3 & $1,90 \%$ \\
\hline Total & 72 & $100,0 \%$ \\
\hline
\end{tabular}

Fonte: Dados da pesquisa.

Ornelas (2003, p. 71) define que "planejar trabalho pericial é, stricto sensu, ordenar os procedimentos técnicos a serem desenvolvidos pelo perito para obter os elementos que permitam oferecer o laudo pericial contábil”. Todavia, pode-se observar que a fase de planejamento foi a responsável pelo menor grau de dedicação médio obtido pela pesquisa. Esta etapa corresponde a apenas 10,60\% do tempo de dedicação e, geralmente, os peritos apenas retiram os autos para análise, estimam o tempo e definem os procedimentos a serem adotados.

Portanto, o que ficou evidente é o reconhecimento por parte dos respondentes de que a fase operacional é a etapa que demanda maior tempo durante os trabalhos, já que, conforme mostrado anteriormente, esta etapa foi responsável por 56,70\% da dedicação dos peritos. 
Proposição de metodologia para determinação dos custos que compõem a hora técnica do perito que atua em litígios do Sistema Financeiro de Habitação Idalberto José das Neves Júnior, Adriano Mariano dos Santos, Ismael Silva Candido

\subsection{Identificação dos Recursos Consumidos}

Uma das premissas básicas do sistema $A B C$ é que as atividades consomem recursos e os produtos consomem atividades. Desta forma, a segunda etapa na construção de uma metodologia baseada neste sistema é a identificação dos recursos consumidos durante o processo de produção do Laudo Pericial Contábil.

Nesse contexto, depois de identificados o volume total de recursos consumidos em todos os tipos de perícias, foi realizado o procedimento de separar a proporção destes recursos que foram consumidos em trabalhos realizados no âmbito do SFH. Para isso, o critério utilizado foi o percentual originado do número de perícias realizadas somente no SFH.

Os grupos compostos por recursos humanos, material direto, tecnologia e insumos foram pré-definidos na construção do questionário na fase de preparação do projeto. Sendo assim, o Gráfico 5 destaca o percentual médio de participação de cada recurso em relação ao total consumido em uma perícia do SFH.

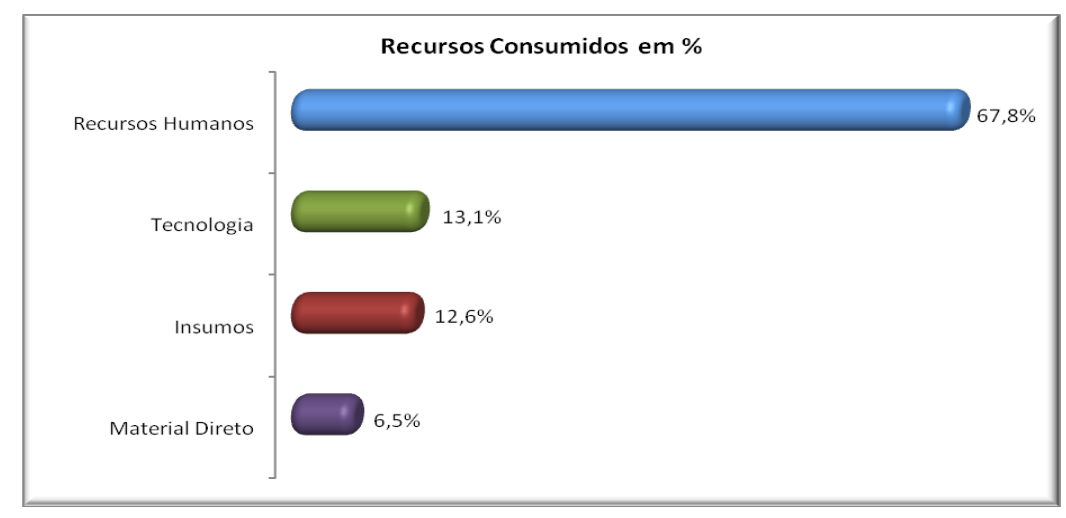

Gráfico 5: Recursos Consumidos em \%

Fonte: Dados da pesquisa.

Observa-se que o custo com Recursos Humanos foi responsável por quase $70 \%$ dos recursos consumidos em uma perícia do SFH. Este fator foi preponderante para o direcionamento dos custos às atividades, já que os demais grupos (Tecnologia, Insumos e Material Direto) foram direcionados às atividades baseados no custo mais representativo, no caso, recursos humanos. 
Proposição de metodologia para determinação dos custos que compõem a hora técnica do perito que atua em litígios do Sistema Financeiro de Habitação Idalberto José das Neves Júnior, Adriano Mariano dos Santos, Ismael Silva Candido

Nesse contexto, para Maher (2001, p. 320), "os recursos fornecidos a uma atividade representam os gastos efetuados na atividade", ou seja, existem custos que independem da utilização pela atividade. O custo da Capacidade não Utilizada representa a parcela destes custos que foram pagos, mas não foram efetivamente utilizados.

A Tabela 2 apresenta o total de recursos fornecidos para a realização de perícias, o custo da capacidade efetivamente utilizada e o custo da capacidade que não foi utilizada pelos peritos durante a realização dos trabalhos.

Tabela 2: Recursos Médios Consumidos em uma perícia do SFH

\begin{tabular}{|c|c|c|c|}
\hline \multicolumn{4}{|c|}{ Recursos Consumidos médios em 1 perícia do SFH } \\
\hline \multirow{3}{*}{$\begin{array}{l}\text { Recursos } \\
\text { Humanos }\end{array}$} & Recursos Fornecidos & $\mathrm{R} \$$ & 698,73 \\
\hline & Capacidade Utilizada & $\mathrm{R} \$$ & 698,73 \\
\hline & Capacidade não Utilizada & $\mathrm{R} \$$ & - \\
\hline \multicolumn{2}{|c|}{ Total - Recursos Humanos } & $\mathbf{R} \$$ & 698,73 \\
\hline \multirow{3}{*}{ Material Direto } & \begin{tabular}{|l|} 
Recursos Fornecidos \\
\end{tabular} & $\mathrm{R} \$$ & 66,76 \\
\hline & Capacidade Utilizada & $\mathrm{R} \$$ & 17,00 \\
\hline & Capacidade não Utilizada & $\mathrm{R} \$$ & 49,76 \\
\hline \multicolumn{2}{|c|}{ Total - Material Direto } & $\mathbf{R} \$$ & 66,76 \\
\hline \multirow{3}{*}{ Tecnologia } & Recursos Fornecidos & $\mathrm{R} \$$ & 135,16 \\
\hline & Capacidade Utilizada & $\mathrm{R} \$$ & 33,91 \\
\hline & Capacidade não Utilizada & $\mathrm{R} \$$ & 101,25 \\
\hline \multicolumn{2}{|c|}{ Total - Tecnologia } & $\mathbf{R} \$$ & 135,16 \\
\hline \multirow{3}{*}{ Insumos } & Recursos Fornecidos & $\mathrm{R} \$$ & 129,88 \\
\hline & Capacidade Utilizada & $\mathrm{R} \$$ & 35,84 \\
\hline & Capacidade não Utilizada & $\mathrm{R} \$$ & 94,04 \\
\hline \multicolumn{2}{|c|}{ Total - Insumos } & $\mathbf{R} \$$ & 129,88 \\
\hline \multicolumn{4}{|c|}{$\underline{\text { Resumo Geral }}$} \\
\hline \multicolumn{2}{|c|}{ Total - Recursos Fornecidos } & $\mathbf{R} \$$ & $1.030,53$ \\
\hline \multicolumn{2}{|c|}{ Total - Capacidade Utilizada } & $\mathbf{R} \$$ & 785,48 \\
\hline \multicolumn{2}{|c|}{ Total -Capacidade não Utilizada } & $\mathbf{R} \$$ & 245,05 \\
\hline
\end{tabular}

Fonte: Dados da pesquisa.

Nesta tabela nota se que o custo com Recursos Humanos não possui capacidade não instalada, pois foi totalmente inserido como recurso consumido das atividades e serviu como parâmetro para o direcionamento dos demais custos. 
Proposição de metodologia para determinação dos custos que compõem a hora técnica do perito que atua em litígios do Sistema Financeiro de Habitação Idalberto José das Neves Júnior, Adriano Mariano dos Santos, Ismael Silva Candido

Além disso, o custo da Capacidade não Utilizada representou $24 \%$ do total dos recursos que são pagos, mas não consumidos pelos peritos no desenvolvimento de suas atividades. Esta informação é muito importante, pois possibilita ao Perito Judicial oficial organizar e gerir melhor os custos de sua capacidade ociosa.

\subsection{Recursos Consumidos por Atividade}

As seções anteriores da pesquisa apresentam o valor dos recursos totais utilizados na realização de perícias do SFH e o quadro de atividades com o grau de dedicação às mesmas, nesta modalidade de resolução de litígios. Todavia, tais informações, se forem abordadas isoladamente, provavelmente, não servirão como ferramenta de gestão dos custos envolvidos em uma perícia do Sistema Financeiro da Habitação.

Sendo assim, fez-se necessário unir o custo total médio de uma perícia realizada no âmbito do Sistema Financeiro da Habitação com o quadro de atividades originada da análise dos questionários. Dessa forma, o direcionador de custos utilizado para a união dos recursos com a atividade foi o grau de dedicação médio.

Com isso, após a identificação da quantidade de horas consumidas, em média, por uma perícia do SFH, pode-se obter o custo total e horas médias auferidas pelos profissionais contábeis no desenvolvimento de seu trabalho. A Tabela 3 apresenta estes resultados. 
Proposição de metodologia para determinação dos custos que compõem a hora técnica do perito que atua em litígios do Sistema Financeiro de Habitação

Idalberto José das Neves Júnior, Adriano Mariano dos Santos, Ismael Silva Candido

Tabela 3: Direcionador de atividades e seus respectivos custos

\begin{tabular}{|c|c|c|c|}
\hline DIRECIONADOR & FASES E ATIVIDADES & $\begin{array}{l}\text { Custo TOTAL } \\
\text { MÉDIO }\end{array}$ & $\begin{array}{l}\text { CuSTO HORA } \\
\text { MÉDIO }\end{array}$ \\
\hline \multirow{15}{*}{ 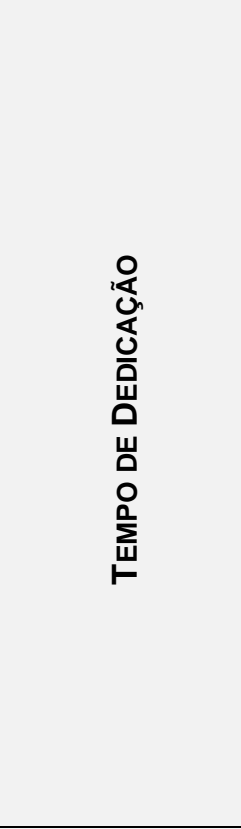 } & PLANEJAMENTO & 83,26 & 3,50 \\
\hline & Retirada e Análise dos autos & 35,35 & 1,49 \\
\hline & $\begin{array}{l}\text { Estimativa do tempo e Identificação da } \\
\text { metodologia a ser adotada }\end{array}$ & 47,91 & 2,01 \\
\hline & OPERACIONAL & 445,37 & 18,71 \\
\hline & Recolhimento e Análise das peças processuais & 172,81 & 7,26 \\
\hline & $\begin{array}{c}\text { Elaboração de planilhas e Efetuação de } \\
\text { cálculos }\end{array}$ & 163,38 & 6,86 \\
\hline & Análise e Resposta aos quesitos & 58,91 & 2,48 \\
\hline & Exame da tabela do agente Financeiro & 19,64 & 0,83 \\
\hline & Exame da legislação vigente & 18,85 & 0,79 \\
\hline & Reunião com assistentes & 11,78 & 0,50 \\
\hline & FINAL & 256,85 & 10,79 \\
\hline & Elaboração e Revisão do Laudo & 194,80 & 8,18 \\
\hline & Revisão de cálculos & 23,56 & 0,99 \\
\hline & Resposta a quesitos adicionais & 23,56 & 0,99 \\
\hline & $\begin{array}{c}\text { Preparação dos anexos e Petição de } \\
\text { Honorários }\end{array}$ & 14,92 & 0,63 \\
\hline & TOTAL & 785,48 & 33,00 \\
\hline
\end{tabular}

Fonte: Dados da pesquisa.

Com relação ao custo da hora técnica, a fase operacional foi responsável pelo maior consumo de recursos em uma perícia do SFH, com destaque para as atividades de "Recolhimento e análise das peças processuais", "Elaboração e efetuação de cálculos" e "Análise e resposta aos quesitos" que foram responsáveis por 50,30\% do total dos custos utilizados nas perícias.

Nesse contexto, de acordo com Sá (2007, p. 36), "para planejar é preciso conhecer os recursos disponíveis, quer humanos, quer materiais, competentes para produzir um laudo de qualidade". Todavia, o que deve ser observado é que os peritos contadores dedicam uma maior parte de seu tempo na execução das atividades e não no planejamento das mesmas, fato este evidenciado no custo apurado de uma perícia do SFH (Tabela 3). 
Proposição de metodologia para determinação dos custos que compõem a hora técnica do perito que atua em litígios do Sistema Financeiro de Habitação Idalberto José das Neves Júnior, Adriano Mariano dos Santos, Ismael Silva Candido

\subsection{Direcionamento das atividades para o Produto}

A última etapa para a construção de uma metodologia $A B C$ voltada para as perícias do SFH é o direcionamento das atividades para o Laudo Pericial Contábil. Todavia, como o trabalho explora apenas este produto, esta fase consistiu em identificar as atividades e associá-las a ele. Nesse sentido, além de identificar as atividades e custos envolvidos em uma perícia do SFH, o $\mathrm{ABC}$ também funciona como uma importante ferramenta para melhoria dos processos do negócio.

Dessa forma, como abordado nas seções anteriores, o valor total da capacidade não utilizada foi de $R \$ 245,45$. A partir daí, no Gráfico 6 se apresenta a disposição desta capacidade ociosa pelas fases inicialmente definidas na pesquisa.

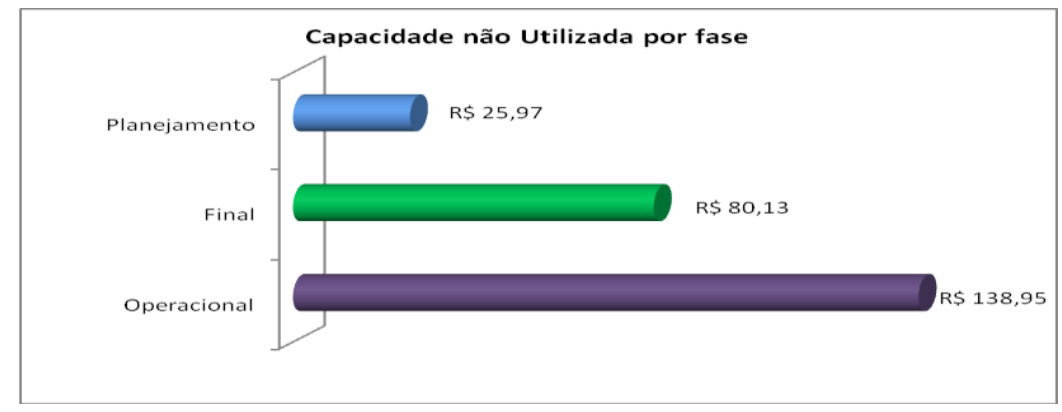

Gráfico 6: Capacidade não Utilizada por fase

Fonte: Dados da pesquisa.

De acordo com Brimson (1999), o ABC é um processo de melhoria de feedback, pois permite a melhoria contínua das atividades e processos em questão. Este aspecto é de suma importância, porque permite que os peritos analisem as atividades e escolham melhores formas de realizá-las, visando sempre aperfeiçoar o processo de produção do Laudo Pericial Contábil.

\section{CONSIDERAÇÕES FINAIS}

O objetivo da pesquisa pode ser considerado atingido, visto que se pode construir um quadro com as atividades que compõem uma perícia realizada no âmbito 
Proposição de metodologia para determinação dos custos que compõem a hora técnica do perito que atua em litígios do Sistema Financeiro de Habitação Idalberto José das Neves Júnior, Adriano Mariano dos Santos, Ismael Silva Candido

do Sistema Financeiro de Habitação. Além disso, a metodologia mostrou-se eficiente na captura dos recursos consumidos e na obtenção do custo da hora técnica por atividade desta modalidade de perícia.

Desta forma, discordando da literatura de perícia contábil que estabelece que a fase de planejamento é a mais importante no desenvolvimento dos trabalhos, os respondentes dedicaram às perícias do SFH no ano de 2009 apenas $10,60 \%$ do tempo total no desenvolvimento destas atividades. A maior parcela do esforço concentrou-se na fase operacional, que deteve $56,7 \%$ de todo o tempo despendido, seguida da fase final que apresentou como atividade mais significativa a "Elaboração e Revisão do Laudo".

Ao aplicar o $A B C$, além de o perito obter o valor dos custos em um grupo de atividades, o uso desta metodologia permite que o profissional perceba o Custo da Capacidade não Utilizada. Na pesquisa, este correspondeu a $24 \%$ do custo total fornecido para a construção do Laudo Pericial Contábil.

Nesse contexto, "Recursos Humanos" foi o recurso mais representativo com $67,80 \%$ do total dos custos disponibilizados para uma perícia do Sistema Financeiro da Habitação, fato este que determinou a forma de direcionamento dos demais custos às atividades. Sendo assim, o trabalho chegou a um custo hora por uma perícia de $R \$$ 33,00 e a um custo total no valor de $\mathrm{R} \$ 785,48$.

A obtenção de apenas 10 questionários respondidos determina que esta análise se enquadre tão somente ao número de peritos respondentes, uma vez que não se pode inferir para a população como um todo. Por outro lado, visto as poucas pesquisas realizadas neste sentido, principalmente na parte de honorários periciais, cabe o mérito do aproveitamento deste estudo como inspiração de trabalhos futuros.

É importante destacar que a pesquisa se limitou a determinar o custo da hora técnica, não possuindo qualquer pretensão de determinar o preço da mesma, uma vez que esta variável possui fatores intrínsecos de difícil mensuração, o que não impede que em trabalhos futuros outros pesquisadores possam identificar tais variáveis e desenvolver uma metodologia de ABC para determinação do preço e não somente dos custos que compõem a hora técnica. 
Proposição de metodologia para determinação dos custos que compõem a hora técnica do perito que atua em litígios do Sistema Financeiro de Habitação Idalberto José das Neves Júnior, Adriano Mariano dos Santos, Ismael Silva Candido

\section{REERÊNCIAS}

ALBERTO, Valder Luiz Palombo. (2002). Perícia Contábil. (3 ed.). São Paulo. Atlas, $220 \mathrm{p}$.

ATKINSON, Anthony A. BANKER, Rajiv D. KAPLAN, Robert S. YOUNG, S Mark. (2000). Contabilidade Gerencial. São Paulo: Atlas, pp 210-300.

BELCHIOR, Elysio O. (1987b). Vocabulário de Termos Econômicos e Financeiros. Rio de Janeiro: Civilização Brasileira, p. 210.

BOISVERT, Hugues. (1999). Contabilidade por Atividades. São Paulo: Atlas, 93 pp.

BRASIL. Lei no 4.380, de 21 de agosto de 1964. Diário Oficial da União de 11 de setembro de $1964 . \quad$ Disponível em: <http://www.planalto.gov.br/ccivil_03/Leis/L4380.htm>. Acesso em 08/set/2009.

BRIMSON, James A. (1996). Contabilidade por atividades. São Paulo: Atlas, 229 pp.

COGAN, Samuel. (1994b). Activity based costing (ABC): a poderosa estratégia empresa empresarial. São Paulo: Pioneira; Rio de Janeiro: Grifos Enterprises, 129 pp.

COGAN, Samuel. (1999a). Custos e preços: formação e análise. São Paulo. Ed. Pioneira. $158 \mathrm{pp}$.

CFC - (Conselho Federal de Contabilidade). Resolução NBC TP 01 e NBC PP 01. Disponível em < http://www.cfc.org.br/sisweb/sre/Default.aspx>. Acesso em: 15/dez/2009. pp 31-46; pp 47-68.

COOPER, Robin e KAPLAN, Robert. (1998). Custo \& Desempenho. São Paulo: Futura, 376 pp.

DRUCKER, P. Activity-Based Management: reasons to Implement. Disponível em: $<$ http://www.activitybasedmgmt.com/Activity_Based_Costing.htm>. Acesso em 26/ago/2009.

EMGEA (Empresa de Avaliação de Ativos). Estatística: Contratos com Dívida Liquidada ou Reestruturada Pessoa Física/Contratos Imobiliários Ativos Inadimplência por Estado. Disponível em: $<$ http://www.emgea.gov.br/portalEmgea/montaDetalheMateria.do?id=902>. Acesso em 05/ago/2009. 
Proposição de metodologia para determinação dos custos que compõem a hora técnica do perito que atua em litígios do Sistema Financeiro de Habitação Idalberto José das Neves Júnior, Adriano Mariano dos Santos, Ismael Silva Candido

FRANCO, J. Nascimento. (1992). Manual Prático da Ação Revisional. São Paulo: Malheiros, $136 \mathrm{pp}$.

HOOG, Wilson Alberto Zappa. (2005). Prova Pericial Contábil. (5 ed.). Curitiba. Juruá, $495 \mathrm{p}$.

KAPLAN, R. S. (1999). Dos Custos à Performance. HSM Management. 03(13): 6-11.

MAHER, Michael; SANTOS, José Evaristo dos (Trad.). (2001). Contabilidade de custos: criando valor para a administração. São Paulo, SP: Atlas, pp 231.

MARTINS, Eliseu. (2006). Contabilidade de custos. (9 ed.). São Paulo: Atlas, p. 139.

ORNELAS, Martinho Maurício Gomes. (2003). Perícia Contábil. (4 ed.). São Paulo: Atlas, $169 \mathrm{pp}$.

PROTÁSIO, João Lucas. A perícia contábil nos financiamentos habitacionais. Disponível em: <http://www.netlegis.com.br/indexRC..jsp?arquivo=detalhesArtigos>, acesso em 10/ago/2009.

RAMASWAMY, Vinita. (2007). New Frontiers: Training Forensic Accountants within the accounting program. Journal of College Teaching \& Learning. 04(09): 31-38.

SÁ, Antônio Lopes de. (2007). Perícia contábil. São Paulo: Atlas, 376 pp.

SANTOS, José Luiz dos. Schmidt, Paulo e GOMES, José Mário Matsumura. (2006). Fundamentos da perícia contábil. São Paulo. Atlas, 123 pp.

SILVA, Antônio Carlos Ribeiro. (2006a). Metodologia de pesquisa aplicada à contabilidade. (2 ed.). São Paulo, 180 pp.

SILVA, Ermes Medeiros da. SILVA, Elio Medeiros da. GONÇALVES, Walter. MUROLO, Afrânio Carlos. (1996b). Estatística para os cursos de Economia, Administração e Ciências Contábeis. (2 ed.). São Paulo: Atlas, p. 23.

VENDRAME, Antonio Carlos. A ética do perito judicial. Disponível em: $<$ http://www.vendrame.com.br/artigos/artigos_ant10.htm>. Acesso em: 20/julho/2009.

VERGARA, Sylvia Constant. (2000). Projetos e Relatórios de Pesquisa em Administração. São Paulo: Atlas, 92 pp.

VIEIRA, Sonia. (2009). Como elaborar questionários. São Paulo: Atlas, 162 pp. 
Proposição de metodologia para determinação dos custos que compõem a hora técnica do perito que atua em litígios do Sistema Financeiro de Habitação

Idalberto José das Neves Júnior, Adriano Mariano dos Santos, Ismael Silva Candido

Data de Submissão: 08/06/2010

Data de Aceite: 28/11/2011 